\title{
Research on Creative Talents Training New Model Based on Modern Vocational Art Education and Career Competitiveness
}

\author{
Xudong $\operatorname{Jin}^{1, \text { a }}$ \\ ${ }^{1}$ Nanjing Institute of Railway Technology, Nanjing, Jiangsu, China, 210031 \\ ${ }^{\mathrm{a}}$ email
}

Keywords: Art Schools, Vocational Art Education, Careers Competitiveness, Talent Training Model, Innovation

\begin{abstract}
Appears difficult employment problems of modern reality of college graduates, the employment problem of graduates of art is more prominent How to solve this problem, we cultivate innovative talents from New Mode of Modern Art Education and Vocational Career Competitiveness discussed. First, summarize the current status of arts graduates of education model, then analyzes the modern professional art college students in Art Education and Employment awareness, careers competitive culture in the problems, and then from the arts curriculum, new composite talent training mode coordinating other aspects of modern vocational education and the arts to enhance the competitiveness of the relationship between students' career, the proposed new pattern for cultivating innovative talents.
\end{abstract}

\section{Introduction}

With college enrollment, art graduates showed a rapid growth trend. However, due to the characteristics of art students and professional limitations, the current employment situation of graduates of art is not very optimistic, individual arts graduates face a "graduation means unemployment" dilemma. Modern art school education transition mode, pay more attention to the cultivation of students' future employability and it is placed in a modern high art college has to face reality. Transformation of Modern Art to do vocational education model to achieve competitiveness with students choosing a combination of culture, society needs to cultivate innovative talents. This will not only help to improve the employment rate of graduates of art, but also the need to promote the healthy development of the art schools. Some Chinese art schools have begun to explore this aspect of the problem, developed a number of art schools to social needs of the market as the new standard of personnel training mode, and achieved initial results, such as Shandong Art Institute, she is trying to get out based on students' future employment of new roads change existing schools of education. However, this change is small, and really has the effect still need the test of time. Overall, China's art still higher vocational institutions focused on students 'professional knowledge of education, there are still many shortcomings in competitiveness to enhance students' career, innovative training model.

\section{The Problems in Innovative Talents Training Model of Arts Education and Careers Competitive in Modern Professional Art School}

Profession and the Market Needs Decoupling. Students good artistic quality, enhance their artistic skills, this is nothing wrong thing. However, many modern professional art schools still follow the curriculum of traditional teaching content, teaching mode, and timely change, change marginally. In art class vocational colleges, for example, or to teach painting, oil painting and other knowledge-based art, some materials has been used for more than ten years, or even longer. This old teaching content and restricts the development of art education in vocational colleges. At the same time, the needs of modern vocational education and community arts market seriously out of line, lagged far behind in social development phenomenon many professional colleges graduates learn the art knowledge appeared in the job when. Plus, vocational art school enrollment, bringing the number of graduates increased year by year, more emphasis on the art students' employment 
problems. In Shandong Province, the latest release of second quarter of 2014, "Shandong Province for graduates in Normal Universities in the second quarter, the employment situation analysis report" for example, art graduates signing rate is almost the lowest. The direct cause of this situation is the Modern Art Vocational Education unreasonable, due to the social needs of the market and out of touch.

The Consciousness of Professional Teacher to Train Student Employment Awareness and Career Competitiveness Awareness is not enough. Art students in professional colleges in the sense of employment and career competitive culture, the lack of professional guidance of teachers is an important factor cannot be ignored. Many art colleges focus only on vocational training of students of art education, resulting in the line of arts education professional education teachers can meet the needs. But awareness of student employment and career training links competitiveness, but often overlooked. Modern professional art school students' career guidance, career aspects of the competitiveness of culture is showing obvious deficiencies. Many professional art school students' employment careers ability, mostly graduate students in the last year by the school guidance classroom teachers. Perhaps teachers in high quality arts education, but students' career guidance, career competition culture is not necessarily good. Shandong Institute of Arts and Science for example, the entire Academy of Fine Arts does not have a specialized vocational training teacher in charge of student employment guidance only by the competent authorities of Church and State College. As one of more than two thousand people a large professional, only a few number of non-professional people in charge of student employment career guidance and employment capacity-building efforts, guiding effect is evident. This practice is a profession of art students' irresponsible, unfair sex education. Any student entering a vocational art school, in addition to receiving art education, the most concerned about is the future of employment. If students spend huge fees (statistics show that art students spent an average capital investment is generally 3 times more students), but in the end even a job I love cannot find work, which is vocational education in art schools failure.

Traditional Art Talents Training Model Innovation is Not Enough. Modern economic development of the market needs more high-quality compound talents. However, the modern professional art education, personnel training, and artistic or traditional training model, the lack of new modern compound talents training mode. Many students ideally positioned for future career blurred, or even simply not established career aspirations, Do more on the sense of career crisis. Drawbacks of this traditional art education personnel training mode, it has been in modern professional accentuates competitive market. The rapid development of modern society calls for Students in vocational colleges on the basis of art education, but also pay attention to the cultivation of students' employment and career awareness competitiveness, to form new compound talents develop new models. However, the modern professional art institutions in this regard, do generally inadequate. At present, the modern professional art schools have not formed an effective comprehensive new training model. Although individual art institutions have begun to explore the establishment of this model, but it takes time and practice.

Administrative Color is Strong and Lacks Long-Term Personnel Training Concept. In China, art schools and other colleges and universities, as public institutions mostly based. Strong administrative color and lacks educational environment, which is the current situation of education in colleges and universities. Art schools also deeply affected by this, the main part of the leaders of art institutions and even appointed by the local government administrative officials play. This has resulted in our art schools of art education, often occur layman leadership situations. New talent in culture, the modern market is the lack of personnel training philosophy, which is one of the important factors causing current situation of art institutions and art education students have a huge gap in employment. In the academic study of modern art education and careers competitive and innovative new training model, based on various subjective or objective reasons, it is always to be avoided. However, this problem cannot be ignored is the reality of existence. Art Students should not be marginalized, should receive appropriate vocational education and employment information to guide the art to develop their career competitiveness. At the school level, it is eager to establish 
art schools as soon as possible based on the students' long-term development of the new training mode. Under strong administrative color educational background, schools lack more modern art education, students choosing competitiveness initiative. Lack of awareness of the initiative has a negative impact on our art schools artistic education and innovation talents.

\section{Recommendation of Innovative Talents Cultivating New Pattern Based on Modern Vocational Art Education and Career Competitiveness}

Take bold innovation of existing arts education curriculum, market-oriented to meet the needs of social development. To achieve a modern vocational art education and students 'future employment combine to enhance students' career competitiveness. The most important point is that the existing Art Education Curriculum in Higher Vocational Art Colleges bold innovation. Specific approach: First, the traditional course content are selectively retained, that is not such a bold innovation negate the previous course, but should be based on the actual needs of teaching bold choice, leave alone the contents of dynamic, excluding those obsolete things. The second is the development of new market closely examining the social needs of modern art talents of the curriculum for market transformation and according to the market need for innovative art education theory, the establishment of the relevant art education programs. Market operation, is the lifeblood of modern art education curriculum lies. Third, exchanges between the various courses in art school and learn from each other, mutual absorption of effective practice, and finally the actual characteristics of their schools to develop their own innovative arts education school arts education programs. Art Education Market improvement and innovation, it can really enhance the careers of students to help competitiveness, thereby helping to establish a new model of art schools Art Talents.

Introduce training professional teachers' personnel, the establishment of an independent team of teachers of vocational education. To change the existing art school students in vocational and career competitive concept culture education guidance talent shortage, not pay attention to the status quo or even ignored. In order to make innovative talents Modern Vocational Education and Training New Career competitive mode, we must pay attention to the relevant introduction and training of professionals. At the same time, people want to conduct specialized training and guidance, with the latest concept of vocational education and improve their literacy teaching skills. To change the past or do not pay attention to this neglected practice, set up special department leadership career guidance in schools, set up a professional instructor team. Only in this way can really do for the art schools of art education in vocational training to enhance students' career competitiveness, to provide protection of human resources. To change the status quo of Modern Art College of Art graduates' employment difficulty, good art student employment guidance, enhance their employability skills imperative careers.

Changing art schools of traditional arts talent training mode, establish a new composite talent training mode. I said to change the personnel training mode of traditional art institutions, not weaken arts education to students' knowledge training. On the contrary, it is to further strengthen the basis of student art literacy and skills training, the more students develop professional skills and literacy training to enhance their careers competitiveness and meet the needs of social development of the market, find your favorite art career. To do this, we must establish a modern art school compound talents training new model. Arts education process in this mode is to social development and the market need to develop more comprehensive high-quality artistic talent to achieve the combination of student and professional competence of artistic accomplishment. Art academies should provide more opportunities for students to practice, to change the past, but only in the graduation internship workplace practices to students enrolled in the first semester of each semester on the development of practical plans. Only through practice, to be able to graduate in art after graduation truly ahead of their own culture of professional practice certain skills, a better job of career choice. In short, the establishment of a new art school compound talents training mode, is the future of art school students to do career guidance fundamental strategic measures. Only in this way, to be able to improve the current lot of art students' graduation means unemployment "dilemma, to be able to provide assistance for the long-term future development of art institutions. 
"To the Chief" of Universities is the inevitable future development of the new era of higher learning. So that more Scholar Educational professionals act as leading universities, government authorities to get rid of the status quo in the past to interfere too much education. I know that to change the current administrative color strong Chinese Universities situation is a very rare thing, which involves the interests of various aspects. However, for long-term development of our future art school for social development and the market need to develop more high-quality artistic talent, even touch the interests of a small number of interest groups, but also bold "to the Chief" reform. The right to development to give full autonomy Art Institute, so that they can truly based on social needs and the characteristics of the new school development personnel training and practice to explore new models. In this regard, the government should adopt policies and strong financial and other means of support, but not to interfere too much. Of course, not to interfere too much and it does not mean laissez-faire government, on the contrary the relevant government departments in charge of education and staff re-locate to straighten their relationship with art institutions and the schools pay more attention to the management of the macro level. In short, as long as that is the general direction of art school no problem in terms of arts education, personnel training, we can give them more development of independent rights. So that it can contribute to real art school from top to bottom to establish long-term, innovative artistic talent training complex strategy.

\section{Conclusions}

Our art schools to do innovative talents Vocational Art Education and Competitiveness Cultivation and practice new patterns. To further study the many art colleges deficiencies exist in this regard, and thus propose targeted solutions. This article explored this matter and to find the problems, causes problems dig, then put forward some of their own solution strategies.

\section{References}

[1] Shi Ling: China Urban Economy, Vol. 29 (2011) No 53, p. 141-144

[2] Zhang Yan: Comprehensive College, Vol. 5 (2013) No 3, p.74-76

[3] Zhou Yong: Music Space, Vol. 14 (2013) No 33, p.161-163

[4] Wang Qianxin: Chinese Scientific and Technical Journals Database, Vol. 21 (2003) No33, p.39-41

[5] Wang Jun: Art Education Research, Vol. 3 (2010) No20, p.102-104 